\title{
Pseudo-papillary orifice
}

An 81-year-old woman was referred to our department due to severe cholangitis after laparoscopic cholecystectomy. She had a high fever and epigastric pain. Blood tests showed elevated levels of $\mathrm{C}$ reactive protein, hepatobiliary enzymes, and bilirubin. Computed tomography and magnetic resonance imaging showed edematous change around major duodenal papilla and there was suspicion of small stones in the bile duct (BD) ( Fig.1). These findings suggested acute cholangitis; therefore, we performed endoscopic biliary drainage. We found periampullary diverticulum and papillary orifice (PO) aligned downward due to a remarkably enlarged papillary mound (\Fig.2a, > Fig.2b, \Video 1). We failed to perform deep cannulation in either the BD or pancreatic duct. During the wire-guided cannulation, we observed the excretion of white milky discharge ( $>$ Fig. $\mathbf{2 c}$ ). We performed needle knife sphincterotomy. Despite pre-cutting, deep cannulation was not completed. Finally, we decided to perform a rendezvous method of percutaneous transhepatic biliary drainage on the second day of hospitalization. We punctured the intrahepatic BD and advanced the guidewire into the duodenum via the papilla. Surprisingly, the guidewire stuck out of another concavity, which was different from what we thought was the PO. Thus, the concavity where the guidewire stuck out revealed to be a "real PO" ( Fig.2d). Despite sweeps by balloon catheter, there was no excretion of milky fluid. After this procedure, the patient's symptoms promptly improved and she had no adverse events.

What was the "pseudo-PO"? In this case, we could not histologically diagnose that lesion. However, the excretion of milky fluid was reported in a case of lymphangioma [1,2], but these are rare. A Brunner's gland hyperplasia [3], mucus secreting polyp [4], and ectopic pancreatic tissue [5] have been known to sometimes have an orifice structure. The ex- cretion of milky fluid by guidewire penetration may indicate lymphatic retention near the papilla. We considered that submucosal lymphatics compressed the distal segment of BD, which could cause cholangitis.

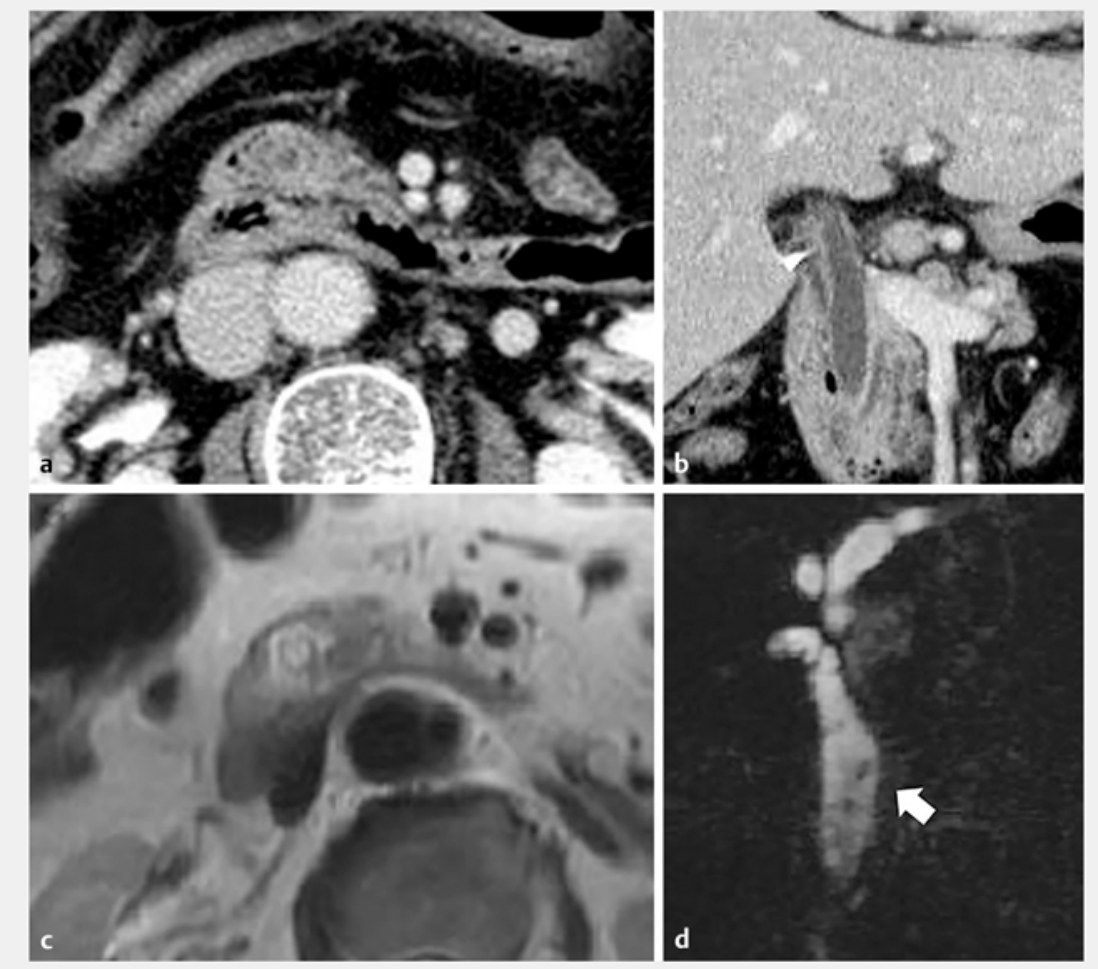

- Fig. 1 Abdominal computed tomography (CT) and magnetic resonance (MR) imaging of major duodenal papilla and the bile duct (BD). a Edematous change was suspected around the major duodenal papilla on axial CT. $\mathbf{b}$ Thickening of the BD wall was seen on coronal CT. c T2-weighted MR image also suggested edematous changes in the major duodenal papilla. d MR cholangiography showed something like sludge (arrow) in the BD. 

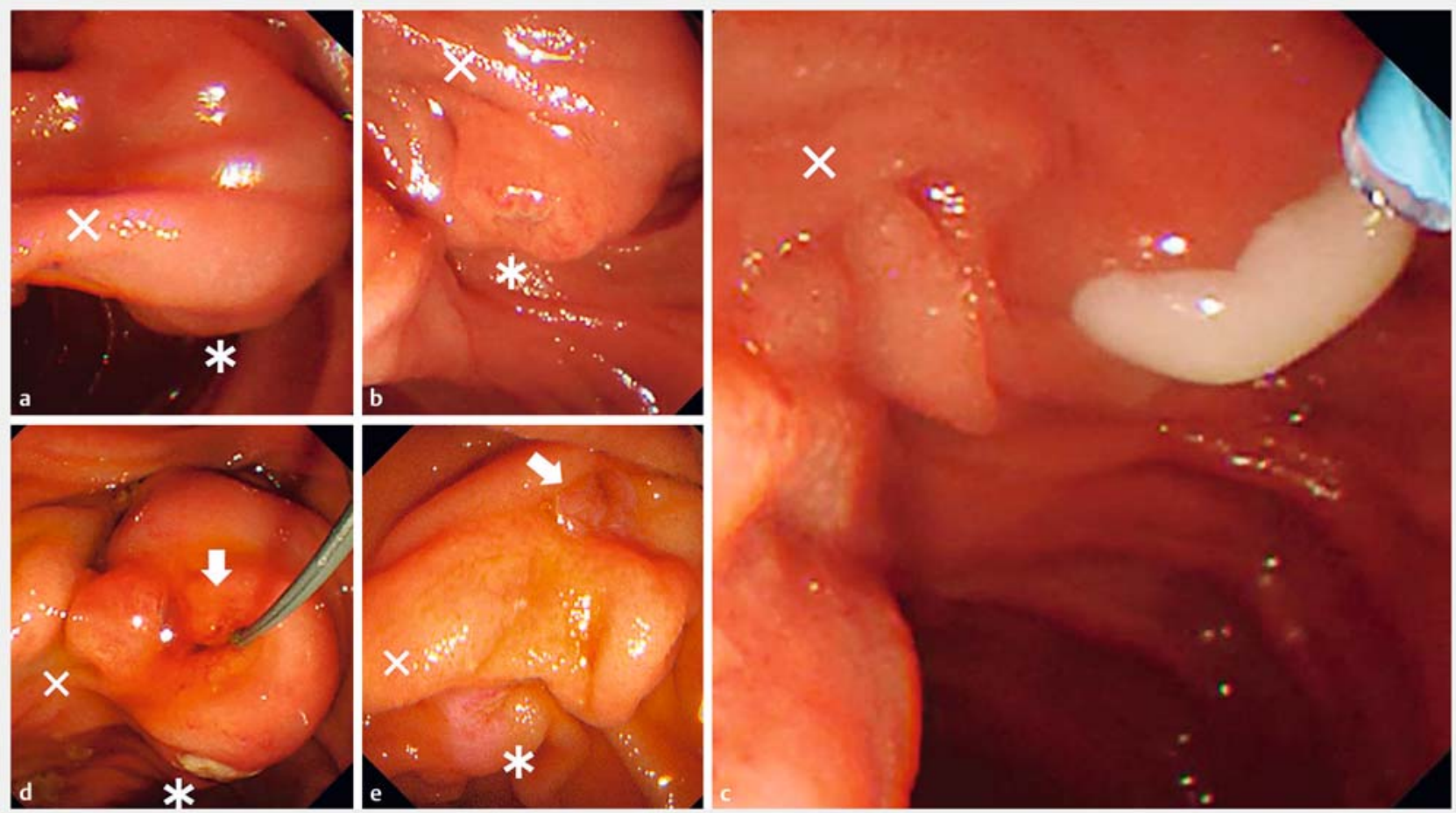

Fig. 2 a Papilla viewed from above. The periampullary diverticulum and enlarged papillary mound were seen. $\mathbf{b}$ Papilla viewed from below. What we initially thought was the papillary orifice $(\mathrm{PO})\left({ }^{*}\right)$ was seen under the covering fold $(\mathrm{X})$. c Milky fluid excretion from the PO during cannulation. $\mathbf{d}$ The real PO (arrow) were identified after a percutaneous rendezvous technique. Whitish ulcerative mucosa indicates the site that we negotiated and which precut revealed to be a "pseudo PO." e Real PO (arrow) and pseudo-PO ( ${ }^{*}$ ) 6 months after the procedures.

\section{DVIDEO}

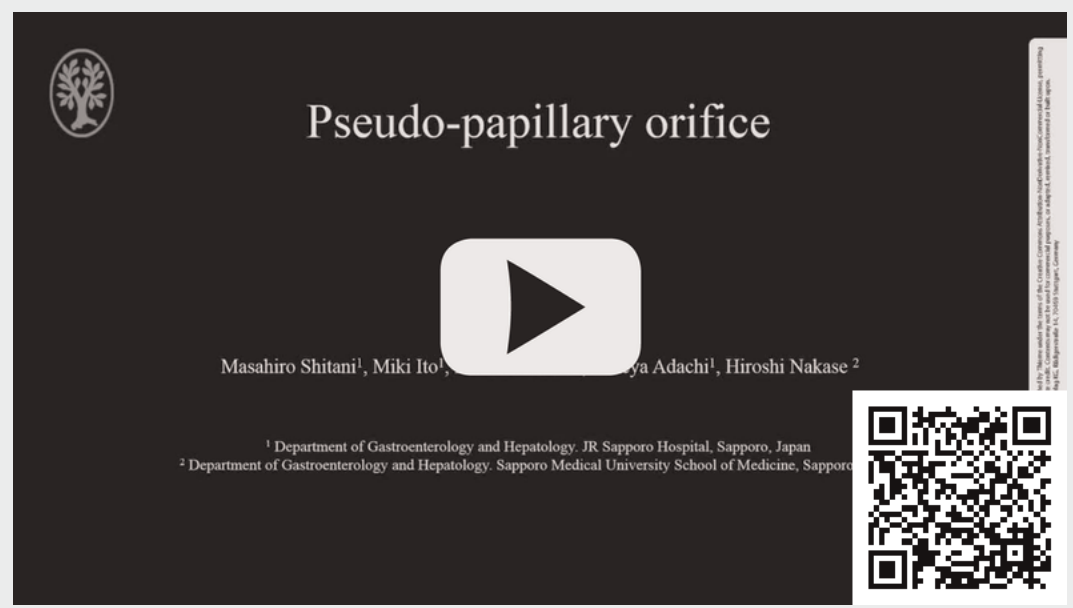

- Video 1 74-year-old woman with cholangitis in whom we failed to perform endoscopic biliary drainage despite wire- and contrast-guided cannulation and needle knife sphincterotomy. Rendezvous cannulation using percutaneous transhepatic biliary drainage was performed.

\section{Competing interests}

The authors declare that they have no conflict of interest.

\section{The authors}

Masahiro Shitani ${ }^{1}$, Miki Ito ${ }^{1}$, Kei Mitsuhashi', Takeya Adachi ${ }^{1}$, Hiroshi Nakase ${ }^{2}$

1 Department of Gastroenterology and Hepatology, JR Sapporo Hospital, Sapporo, Japan

2 Department of Gastroenterology and Hepatology, Sapporo Medical University School of Medicine, Sapporo, Japan

\section{Corresponding author}

\section{Masahiro Shitani, MD,PhD}

Department of Gastroenterology and Hepatology, JR Sapporo Hospital, N-3, E-1, Chuoku, Sapporo, Hokkaido, 060-0033, Japan

Fax: +81-11-208-7170

shitani@sapmed.ac.jp 


\section{References}

[1] Sriram PV, Weise C, Seitz U et al. Lymphangioma of the major duodenal papilla presenting as acute pancreatitis: treatment by endoscopic snare papillectomy. Gastrointest Endosc 2000; 51: 733-736

[2] Iwamuro M, Kawai Y, Takata K et al. Observation of lymphangioma of the duodenum by a magnifying endoscope with a narrowband imaging system. Case Rep Gastroenterol 2013; 7: 229-233
[3] Tanaka H, Matsui S, Kashida H et al. Endoscopic submucosal dissection of duodenal adenocarcinoma arising from Brunner's gland. Annals Gastroenterol 2019; 32: 316

[4] Tanaka M, Fujikura S, Saito S et al. Mucus secreting polyp of the Duodenum. Gastroenterol Endosc 1980; 22: 247-261

[5] Straatman J, Meester RJ, Grieken NC et al. Clinical picture: multiple sites of ectopic pancreatic tissue. Springerplus 2015; 4: 293

\section{Bibliography}

Endosc Int Open 2021; 09: E1321-E1323

DOI 10.1055/a-1490-8459

ISSN 2364-3722

(c) 2021. The Author(s).

This is an open access article published by Thieme under the terms of the Creative Commons Attribution-NonDerivativeNonCommercial License, permitting copying and reproduction so long as the original work is given appropriate credit. Contents may not be used for commercial purposes, or adapted, remixed, transformed or built upon. (https:// creativecommons.org/licenses/by-nc-nd/4.0/)

Georg Thieme Verlag KG, Rüdigerstraße 14, 70469 Stuttgart, Germany 